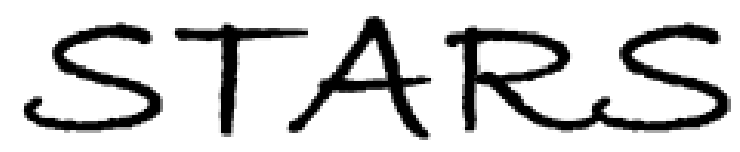

University of Central Florida

STARS

$1-1-2007$

\title{
Cathodoluminescence studies of carrier concentration dependence for the electron-irradiation effects in $\mathrm{p}-\mathrm{GaN}$
}

\author{
O. Lopatiuk-Tirpak \\ University of Central Florida \\ L. Chernyak \\ University of Central Florida \\ Y. L. Wang \\ F. Ren
}

S. J. Pearton

See next page for additional authors

Find similar works at: https://stars.library.ucf.edu/facultybib2000

University of Central Florida Libraries http://library.ucf.edu

This Article is brought to you for free and open access by the Faculty Bibliography at STARS. It has been accepted for inclusion in Faculty Bibliography 2000s by an authorized administrator of STARS. For more information, please contactSTARS@ucf.edu.

\section{Recommended Citation}

Lopatiuk-Tirpak, O.; Chernyak, L.; Wang, Y. L.; Ren, F.; Pearton, S. J.; Gartsman, K.; and Feldman, Y., "Cathodoluminescence studies of carrier concentration dependence for the electron-irradiation effects in p-GaN" (2007). Faculty Bibliography 2000s. 7372.

https://stars.library.ucf.edu/facultybib2000/7372

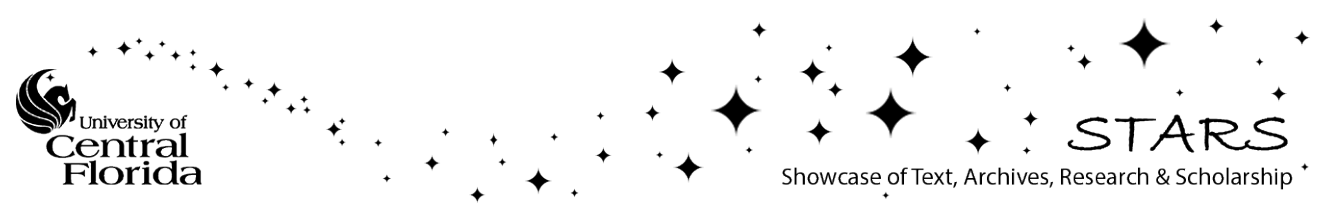


Authors

O. Lopatiuk-Tirpak, L. Chernyak, Y. L. Wang, F. Ren, S. J. Pearton, K. Gartsman, and Y. Feldman 


\section{Cathodoluminescence studies of carrier concentration dependence for the electron- irradiation effects in $p-\mathrm{GaN}$}

Cite as: Appl. Phys. Lett. 90, 172111 (2007); https://doi.org/10.1063/1.2733620

Submitted: 13 March 2007 . Accepted: 30 March 2007 . Published Online: 26 April 2007

O. Lopatiuk-Tirpak, L. Chernyak, Y. L. Wang, F. Ren, S. J. Pearton, K. Gartsman, and Y. Feldman

\section{ARTICLES YOU MAY BE INTERESTED IN}

Cathodoluminescence studies of the electron injection-induced effects in GaN Applied Physics Letters 82, 3680 (2003); https://doi.org/10.1063/1.1578514

Gamma irradiation impact on electronic carrier transport in AIGaN/GaN high electron mobility transistors

Applied Physics Letters 102, 062102 (2013); https://doi.org/10.1063/1.4792240

Depletion-mode $\mathrm{Ga}_{2} \mathrm{O}_{3}$ metal-oxide-semiconductor field-effect transistors on $\beta-\mathrm{Ca}_{2} \mathrm{O}_{3}(010)$ substrates and temperature dependence of their device characteristics

Applied Physics Letters 103, 123511 (2013); https://doi.org/10.1063/1.4821858
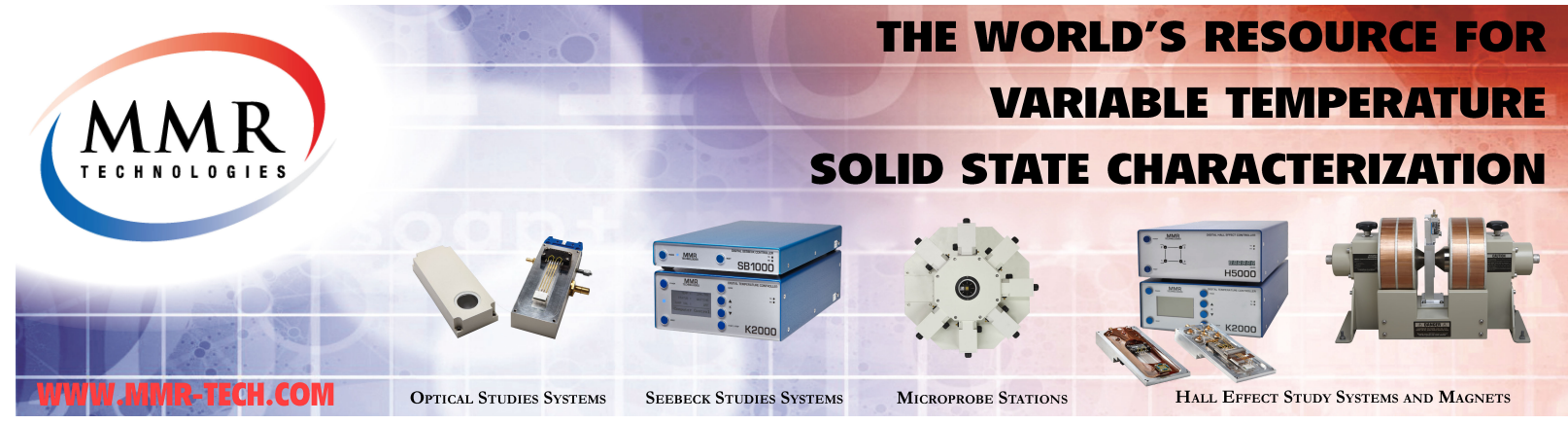


\title{
Cathodoluminescence studies of carrier concentration dependence for the electron-irradiation effects in $p$-GaN
}

\author{
O. Lopatiuk-Tirpak and L. Chernyak ${ }^{\text {a) }}$ \\ University of Central Florida, Orlando, Florida 32816-2385 \\ Y. L. Wang, F. Ren, and S. J. Pearton \\ University of Florida, Gainesville, Florida 32611 \\ K. Gartsman and Y. Feldman \\ Weizmann Institute of Science, Rehovot 76100, Israel
}

(Received 13 March 2007; accepted 30 March 2007; published online 26 April 2007)

\begin{abstract}
Electron-irradiation increase of nonequilibrium carrier lifetime was studied as a function of hole concentration in Mg-doped GaN. Temperature-dependent cathodoluminescence (CL) studies yielded activation energies of 344, 326, 237, and $197 \mathrm{meV}$ for samples with hole concentrations of $2 \times 10^{16}, 9 \times 10^{16}, 3 \times 10^{18}$, and $7 \times 10^{18} \mathrm{~cm}^{-3}$, respectively. The systematic decay of activation energy with carrier concentration was found to be consistent with $\mathrm{Mg}$ acceptors, indicating the involvement of the latter levels in irradiation-induced lifetime changes. (C) 2007 American Institute of Physics. [DOI: 10.1063/1.2733620]
\end{abstract}

Over the past several years, the effects of irradiation by the low energy electron beam on the minority carrier diffusion length and lifetime have been investigated in wide band gap semiconductors, particularly in $\mathrm{ZnO}$ and $\mathrm{GaN}$. Electron beam induced current (EBIC) and cathodoluminescence (CL) measurements have demonstrated that the diffusion length $(L)$ and lifetime of nonequilibrium minority carriers $(\tau)$ in $p$-type $\mathrm{GaN}$ and $\mathrm{ZnO}$ can be significantly increased by the exposure to the beam of a scanning electron microscope. ${ }^{1,2}$ In all cases, activation energy for the electron injection effects was shown to be consistent with the activation energies of the dominant acceptor species, indicating the involvement of acceptor levels in the electron-irradiationinduced phenomena. Since acceptors in $\mathrm{GaN}$, as well as in $\mathrm{ZnO}$, tend to be relatively deep (at least several hundred $\mathrm{meV}$ above the valence band maximum), only a small fraction of the acceptor atoms is ionized at or near the room temperature. For $\mathrm{Mg}$ acceptor level which has thermal activation energy of about $200 \mathrm{meV}$ in $\mathrm{GaN}$, ionized atoms constitute about $1 \%$ of total concentration. ${ }^{3}$ It has been proposed that under electron irradiation, the abundant neutral (nonionized) $\mathrm{Mg}$ atoms act as electron traps, suppressing the recombination of nonequilibrium carriers that normally proceeds through these levels. This leads to an increase in the lifetime of nonequilibrium electrons in the conduction band, and hence, to greater minority carrier diffusion length in $p$-type semiconductors. ${ }^{4}$

In order to provide further evidence of the involvement of $\mathrm{Mg}$ acceptor levels in the electron-irradiation effects, the present work focuses on determining the activation energy of electron-irradiation effect on nonequilibrium carrier lifetime as a function of acceptor concentration. The activation energy was determined by performing variable-temperature cathodoluminescence measurements under continuous irradiation by the beam of the scanning electron microscope (SEM).

${ }^{a)}$ Electronic mail: chernyak@physics.ucf.edu
Experiments were conducted on four 3-5 $\mu \mathrm{m}$ thick commercially available GaN epitaxial films (TDI, Inc.) doped with different concentrations of magnesium. The net hole concentrations were determined by Hall effect measurements and are shown in Table I. CL measurements were conducted in situ in the Philips XL30 SEM integrated with Gatan MonoCL cathodoluminescence system. An accelerating voltage of $20 \mathrm{kV}$ was used. The decay of near-band-edge (NBE) luminescence intensity was monitored as a function of duration of irradiation by the electron beam. The SEM is also fitted with a hot stage and an external temperature controller (Gatan) allowing for temperature-dependent experiments. The rates of NBE intensity decay were measured at different temperatures ranging from 25 to $125^{\circ} \mathrm{C}$. Note that at each temperature, the measurements were performed on a previously unexposed location.

The irradiation-induced decay of NBE luminescence intensity is demonstrated in Fig. 1 using sample 1 as an example (see Table I). The room-temperature spectra shown correspond to about $0,1600,2500$, and $4000 \mathrm{~s}$ of continuous irradiation by the SEM beam. Since luminescence intensity $I$ is inversely proportional to $\tau$, the systematic decay of intensity indicates that irradiation by the electron beam increases the lifetime of nonequilibrium electronic carriers. The carrier diffusion length is proportional to the square root of lifetime $\left[L=(D \tau)^{1 / 2}\right]$, where $D$ is diffusivity; the diffusion length, in turn, had been shown by EBIC measurements to be directly proportional to the duration of irradiation $(t) .{ }^{2}$ Therefore, lifetime can be expected to increase quadratically with $t$, as is

TABLE I. Room-temperature hole concentrations and activation energies $\left(E_{A}\right)$ for the electron-irradiation-induced lifetime increase in GaN:Mg

\begin{tabular}{ccc}
\hline \hline Sample No. & $\begin{array}{c}\text { Hole concentration } \\
\left(\mathrm{cm}^{-3}\right)\end{array}$ & $\begin{array}{c}E_{A} \\
(\mathrm{meV})\end{array}$ \\
\hline 1 & $2 \times 10^{16}$ & $344 \pm 43$ \\
2 & $9 \times 10^{16}$ & $326 \pm 48$ \\
3 & $3 \times 10^{18}$ & $237 \pm 20$ \\
4 & $7 \times 10^{18}$ & $197 \pm 7$ \\
\hline \hline
\end{tabular}




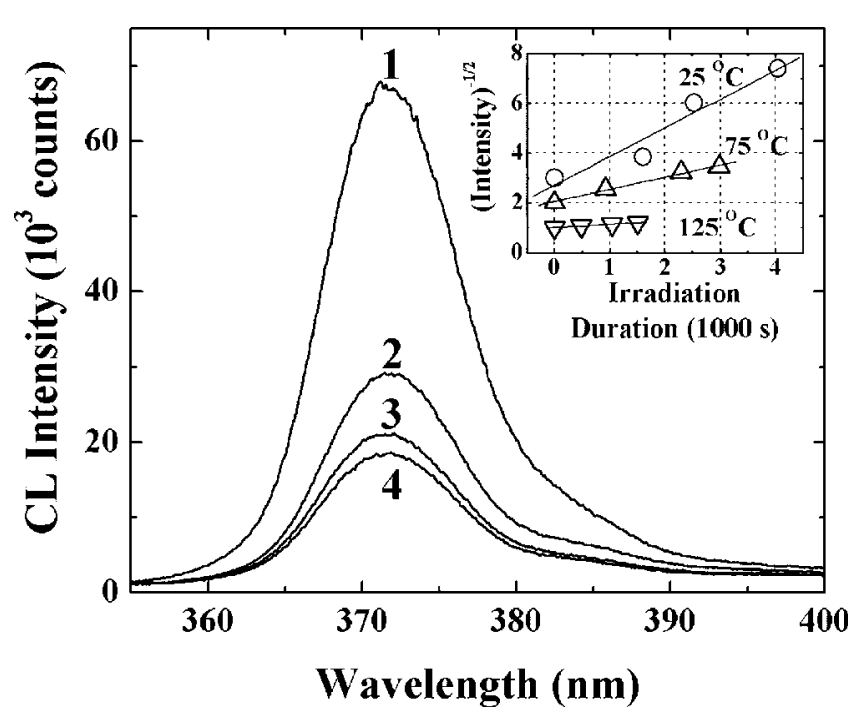

FIG. 1. Room-temperature cathodoluminescence spectra of sample 1 under continuous irradiation by the SEM beam. Spectra 1-4 correspond to 0, 1611, 2529, and $4039 \mathrm{~s}$ of irradiation, respectively. Inset: Variable-temperature dependence of inverse square root of intensity on duration of electron irradiation and the linear fits (solid lines) with the rate $R$. Intensity values were normalized with respect to their initial values at each temperature; the data sets were vertically offset for clarity.

demonstrated experimentally by the decay of intensity of the NBE luminescence. The inset of Fig. 1 shows that there exists a linear dependence between $(1 / I)^{1 / 2}$, which is proportional to the lifetime of the nonequilibrium carriers in the band, and the duration of irradiation. In this and subsequent figures, intensity was normalized with respect to its initial value.

The results of CL measurements performed on sample 1 at elevated temperatures are also shown in the inset of Fig. 1. The progressively lower rates of intensity decay indicate that a concurrent, thermally activated process opposes the irradiation-induced lifetime increase. In the scheme of the mechanism suggested above, this process most likely consists of the transition of the electron from the $\mathrm{Mg}$ trap to the valence band. Thermal activation of this process indicates that there exists an energy barrier that must be overcome before the latter transition can take place. As the temperature increases, these transitions occur more frequently, reestablishing the original recombination pathway and resulting in the slower rate of lifetime increase.

The relationship between the rate $(R)$ and temperature $(T)$ of the sample allows to estimate the activation energy of the irradiation-induced intensity decay: ${ }^{5}$

$$
R=R_{0} \exp \left(\frac{E_{A}}{2 k T}\right)
$$

In Eq. (1), $R_{0}$ is a scaling constant, $E_{A}$ is the activation energy, and $k$ is Boltzmann's constant. The activation energies for all four samples were extracted from the plots shown in Fig. 2. For sample 1, the activation energy of $344 \pm 43 \mathrm{meV}$ was obtained. While this value is considerably higher than the frequently quoted thermal activation energy of $\mathrm{Mg}$ acceptor $(\sim 200 \mathrm{meV})$, it is not in contradiction to the values of the optical ionization energy of $\mathrm{Mg}$ in GaN. Several photoluminescence studies, particularly those conducted in earlier years, when $\mathrm{Mg}$ doping yielded only moderate hole concentrations, resulted in the ionization energies on the order of
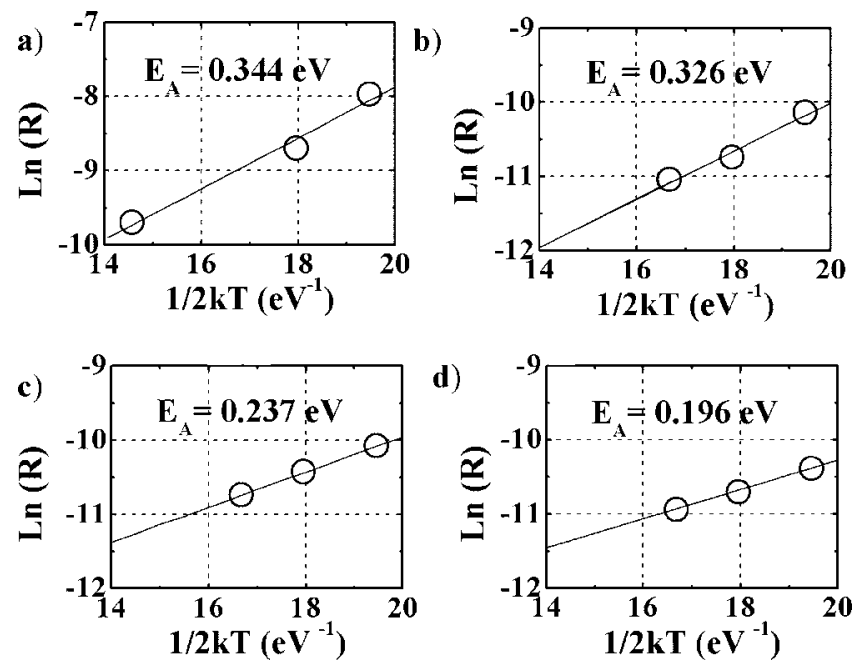

FIG. 2. Arrhenius plots of $R$ as a function of sample temperature for samples 1-4 [plots (a)-(d), respectively]. The linear fit with Eq. (1) (solid lines) yielded activation energies shown in each plot.

$300 \mathrm{meV} .^{6,7}$ Note that the values of optical ionization energies (i.e., those obtained under nonequilibrium conditions, such as photo- and cathodoluminescence experiments) have been shown to differ significantly from thermal activation energies (for instance, those derived from Hall measurements), implying the existence of significant relaxation energy of $\mathrm{Mg}$ dopants. 6,8

Further evidence of $\mathrm{Mg}$ involvement in irradiationinduced lifetime increase can be derived from the dependence of $E_{A}$ on carrier concentration, $p$, which is related to $\mathrm{Mg}$ doping levels. The activation energy of electronirradiation effect was shown to decrease systematically with increasing hole concentration (see Table I). Incidentally, the relationship between acceptor activation energies and hole concentration is well known and has been explored in $\mathrm{GaN}$ and other semiconductors. ${ }^{9,10}$ It has been attributed to a number of causes, not necessarily mutually exclusive, including the formation of the band-tail states that extend into the forbidden gap, the broadening of the acceptor band in the gap, and the reduction of binding energy due to Coulomb interaction between the holes in the valence band and the ionized acceptor states. ${ }^{11}$ The decrease of activation energy is often described by the following equation:

$$
E_{A}\left(N_{A}^{-}\right)=E_{A}(0)-\alpha\left(N_{A}^{-}\right)^{1 / 3},
$$

where $N_{A}^{-}$is the concentration of ionized acceptors, $E_{A}(0)$ is the ionization energy at very low doping levels, and $\alpha$ is a constant accounting for geometrical factors as well as for the properties of the material and, according to theoretical calculations, has the following form:

$$
\alpha=\left(\Gamma(2 / 3) \frac{4 \pi}{3}\right)\left(\frac{q^{2}}{4 \pi \varepsilon}\right),
$$

where $\Gamma(x)$ is the gamma function of argument $x, q$ is the elementary charge, and $\varepsilon$ is the dielectric constant, taken to be $9.5 \varepsilon_{0}{ }^{10}$

The fit of experimentally obtained activation energies with Eq. (2) is shown in Fig. 3. The values of $N_{A}^{-}$were derived under the assumption that $N_{A}^{-}-N_{D}^{+}=p$, where $N_{D}^{+}$is the density of ionized shallow donors and based on the manufacturer's specification is approximately $1 \times 10^{17} \mathrm{~cm}^{-3}$. 


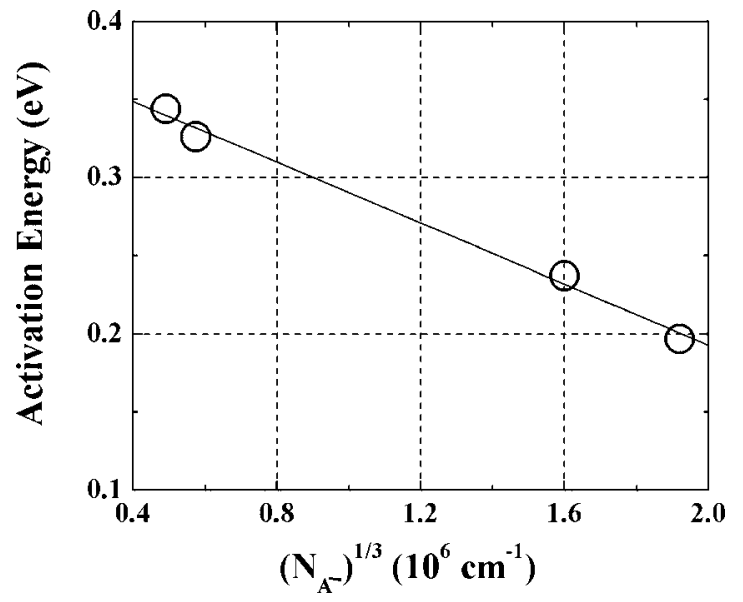

FIG. 3. Decrease of activation energy of electron-irradiation effect as a function of ionized acceptor concentration and the linear fit (solid line) with Eq. (2).

From the fit in Fig. 3, $\alpha=9.74 \times 10^{-8} \mathrm{eV} \mathrm{cm}$, which is comparable to the results of the calculation using Eq. (3) (3.32 $\left.\times 10^{-8} \mathrm{eV} \mathrm{cm}\right)$. Note that it is also within the order of magnitude of the value reported for acceptor activation energy in $p-\mathrm{ZnO}^{12}$

In summary, the activation energy for the electronirradiation-induced lifetime increase was studied as a function of net hole concentration using variable-temperature cathodoluminescence measurements. Since $E_{A}$ was shown to decay in a manner consistent with that for $\mathrm{Mg}$ acceptor activation, we conclude that the electron-irradiation phenomena involve $\mathrm{Mg}$ acceptors, likely through electron trapping on nonionized levels.
The support of the NATO Science for Peace grant (SfP 981939) is gratefully acknowledged. Work at UCF was also partially supported through ACS/PRF (40501-AC10) and NSF (ECS 0422604) grants.

${ }^{1}$ W. Burdett, O. Lopatiuk, L. Chernyak, M. Hermann, M. Stutzmann, and M. Eickhoff, J. Appl. Phys. 96, 3556 (2004); O. Lopatiuk, W. Burdett, L. Chernyak, K. P. Ip, Y. W. Heo, D. P. Norton, S. J. Pearton, B. Hertog, P. P. Chow, and A. Osinsky, Appl. Phys. Lett. 86, 012105 (2005); O. LopatiukTirpak, L. Chernyak, F. X. Xiu, J. L. Liu, S. Jang, F. Ren, S. J. Pearton, A. Osinsky, and P. Chow, J. Appl. Phys. 100, 086101 (2006).

${ }^{2}$ L. Chernyak, A. Osinsky, V. Fuflyigin, and E. F. Schubert, Appl. Phys. Lett. 77, 875 (2000).

${ }^{3}$ D. J. H. Lambert, M. M. Wong, U. Chowdhury, C. Collins, T. Li, H. K. Kwon, B. S. Shelton, T. G. Zhu, J. C. Campbell, and R. D. Dupuis, Appl. Phys. Lett. 77, 1900 (2000).

${ }^{4}$ L. Chernyak, A. Osinsky, and A. Schulte, Solid-State Electron. 45, 1687 (2001).

${ }^{5}$ M. Eckstein and H. U. Habermeier, J. Phys. IV 1, 23 (1991).

${ }^{6}$ J. Z. Li, J. Y. Lin, H. X. Jiang, A. Salvador, A. Botchkarev, and H. Morkoc, Appl. Phys. Lett. 69, 1474 (1996).

${ }^{7}$ M. Smith, G. D. Chen, J. Y. Lin, H. X. Jiang, M. A. Khan, and C. J. Sun, Appl. Phys. Lett. 67, 3295 (1995); M. Smith, G. D. Chen, J. Y. Lin, H. X. Jiang, A. Salvador, B. N. Sverdlov, A. Botchkarev, H. Morkoc, and B. Goldenberg, ibid. 68, 1883 (1996); S. Strife and H. Morkoc, J. Vac. Sci. Technol. B 10, 1237 (1992).

${ }^{8}$ C. G. Van de Walle and J. Neugebauer, J. Appl. Phys. 95, 3851 (2004).

${ }^{9}$ P. P Debye and E. M. Comwell, Phys. Rev. 93, 639 (1954); W. Gotz, R. S. Kern, C. H. Chen, H. Liu, D. A. Steigerwald, and R. M. Fletcher, Mater. Sci. Eng., B 59, 211 (1999).

${ }^{10}$ P. Kozodoy, H. L. Xing, S. P. DenBaars, U. K. Mishra, A. Saxler, R. Perrin, S. Elhamri, and W. C. Mitchel, J. Appl. Phys. 87, 1832 (2000).

${ }^{11}$ M. G. Cheong, K. S. Kim, C. S. Kim, R. J. Choi, H. S. Yoon, N. W. Namgung, E. K. Suh, and H. J. Lee, Appl. Phys. Lett. 80, 1001 (2002).

${ }^{12}$ O. Lopatiuk-Tirpak, W. V. Schoenfeld, L. Chernyak, F. X. Xiu, J. L. Liu, S. Jang, F. Ren, S. J. Pearton, A. Osinsky, and P. Chow, Appl. Phys. Lett. 88, 202110 (2006). 